\title{
Comment on "Efficacy of 7-Day and 14-Day Triple Therapy Regimens for the Eradication of Helicobacter pylori: A Comparative Study in a Cohort of Romanian Patients"
}

\author{
Amin Talebi Bezmin Abadi \\ Department of Bacteriology, Faculty of Medical Sciences, Tarbiat Modares University, P.O. Box 14115-111, Tehran, Iran \\ Correspondence should be addressed to Amin Talebi Bezmin Abadi; amin.talebi@modares.ac.ir
}

Received 30 December 2015; Accepted 14 January 2016

Academic Editor: Spiros D. Ladas

Copyright (C) 2016 Amin Talebi Bezmin Abadi. This is an open access article distributed under the Creative Commons Attribution License, which permits unrestricted use, distribution, and reproduction in any medium, provided the original work is properly cited.

We read with great interest the paper by Arama et al., "Efficacy of 7-Day and 14-Day Triple Therapy Regimens for the Eradication of Helicobacter pylori: A Comparative Study in a Cohort of Romanian Patients" [1]. In this randomized prospective study, they compared the eradication rates of Helicobacter pylori infection by a 7-day and 14-day anti-HP regimen. $H$. pylori is an infectious disease and the goal of treatment is to cure the infection $[2,3]$. This transmissible infection is significantly associated with various digestive diseases and is a main cause of mortality worldwide. Taking together, $H$. pylori is a chronic infectious agent; thus, an ultimate demand is to eradicate it [4]. However, some points we found may help to draw better conclusion.

(1) Current reported results are not unexpected within this population. The main limitation of current study is the small sample size which may not support actual representative of this population. Accordingly, a study with larger number of $H$. pylori positive patients is required to draw a better conclusion.

(2) The optimal duration for $H$. pylori eradication is still controversial. The authors concluded that two weeks of anti-H. pylori regimen is preferable than 7 days. However, they did not mention the rationale for extra side effects due to the increased duration of this therapy. So, it can be a good opportunity to rethink about optimal $H$. pylori treatment duration.
(3) Being cost-effective is an important factor for an optimum duration of $H$. pylori eradication regimens. However, this item is influencing 14-day treatment.

Conclusively, an optimal first-line $H$. pylori eradication therapy has to be discovered already. Certainly, preantibiotic susceptibility tests are inevitable approach in $H$. pylori therapy.

\section{Disclaimer}

The contents of this review article are the sole responsibility of the author and necessarily represent personal perspective.

\section{Conflict of Interests}

The author declares that the research was conducted in the absence of any commercial or financial relationships that could be construed as a potential conflict of interests.

\section{References}

[1] S. S. Arama, C. Tiliscan, C. Negoita et al., "Efficacy of 7day and 14-day triple therapy regimens for the eradication of Helicobacter pylori: a comparative study in a cohort of romanian patients," Gastroenterology Research and Practice, vol. 2016, Article ID 5061640, 7 pages, 2016. 
[2] D. Y. Graham, Y.-C. Lee, and M.-S. Wu, "Rational Helicobacter pylori therapy: evidence-based medicine rather than medicinebased evidence," Clinical Gastroenterology and Hepatology, vol. 12, no. 2, pp. 177.e3-186.e3, 2014.

[3] A. T. Abadi, T. Taghvaei, A. Ghasemzadeh, and A. M. Mobarez, "High frequency of A2143G mutation in clarithromycinresistant Helicobacter pylori isolates recovered from dyspeptic patients in Iran," Saudi Journal of Gastroenterology, vol. 17, no. 6, pp. 396-399, 2011.

[4] A. T. B. Abadi, "Therapy of Helicobacter pylori: present medley and future prospective," BioMed Research International, vol. 2014, Article ID 124607, 7 pages, 2014. 


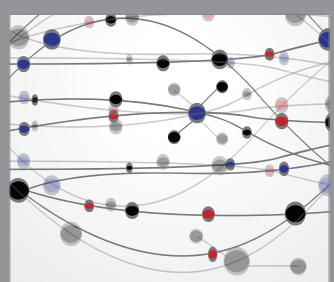

The Scientific World Journal
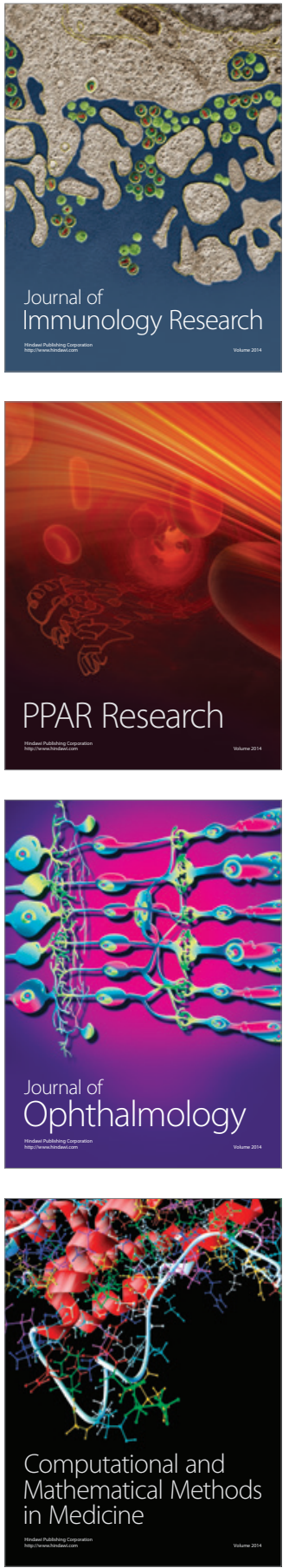

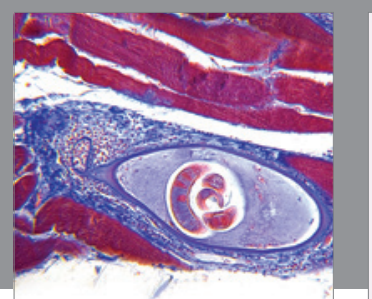

Gastroenterology Research and Practice

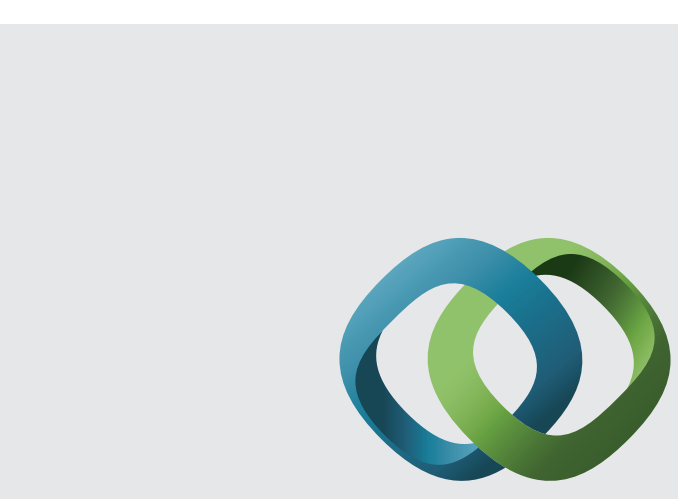

\section{Hindawi}

Submit your manuscripts at

http://www.hindawi.com
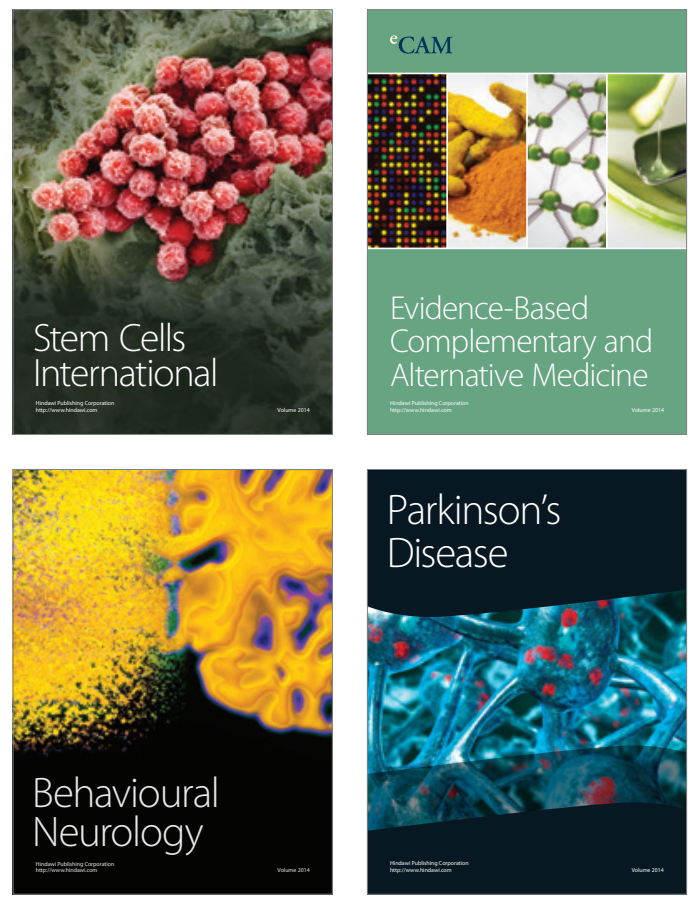
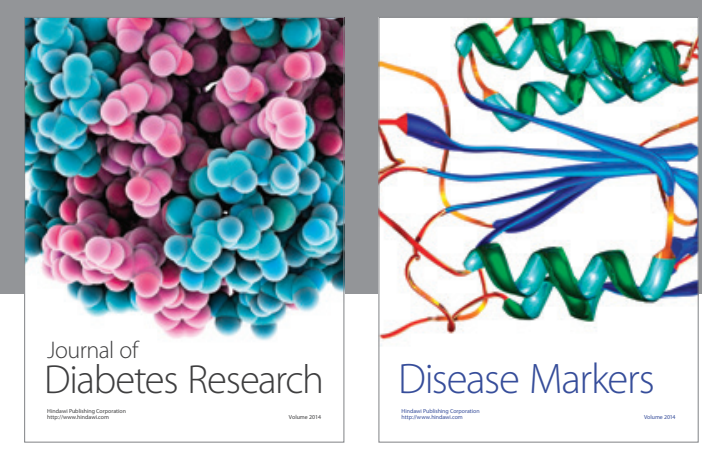

Disease Markers
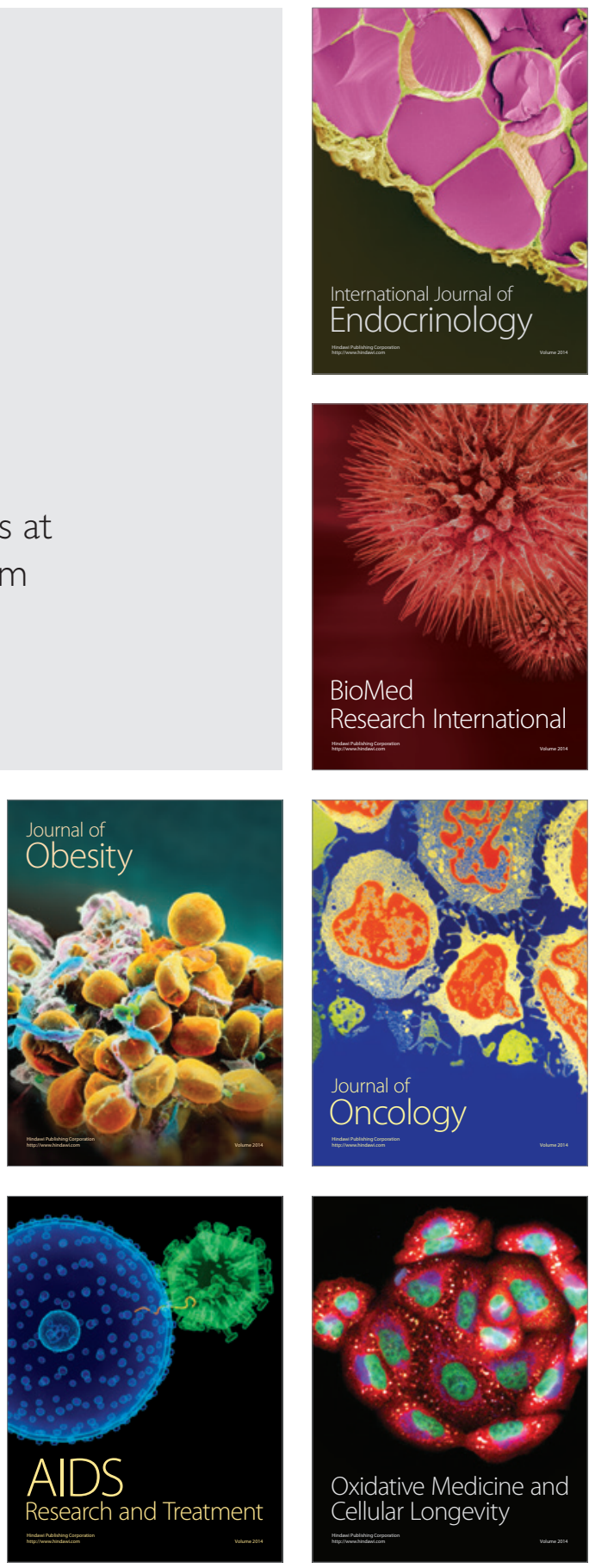